\title{
Frequency and Duration of Daily Smartphone Usage in Relation to Personality Traits
}

\author{
Felix Beierle ${ }^{1 *}$, Thomas Probst ${ }^{2}$, Mathias Allemands ${ }^{3,4}$, Johannes Zimmermann 5 , \\ Rüdiger Pryss 6 , Patrick Neff ${ }^{4}$, , Winfried Schlee ${ }^{7}$, Stefan Stieger ${ }^{8}$ \& Sanja Budimir ${ }^{2}$ \\ 1 Service-centric Networking, Telekom Innovation Laboratories, Technische Universität Berlin, Berlin, Germany \\ ${ }^{2}$ Department for Psychotherapy and Biopsychosocial Health, Danube University Krems, Krems an der Donau, Austria \\ ${ }^{3}$ Department of Psychology, University of Zurich, Zurich, Switzerland \\ ${ }^{4}$ University Research Priority Program "Dynamics of Healthy Aging", University of Zurich, Switzerland \\ ${ }^{5}$ Department of Psychology, University of Kassel, Kassel, Germany \\ ${ }^{6}$ Institute of Clinical Epidemiology and Biometry, University of Würzburg, Würzburg, Germany \\ 7 Department for Psychiatry and Psychotherapy, University of Regensburg, Regensburg, Germany \\ ${ }^{8}$ Department of Psychology and Psychodynamics, Karl Landsteiner University of Health Sciences, Krems an der Donau, Austria
}

\begin{abstract}
Objectives: Daily life behavior can be studied by smart mobile devices. This study investigated associations between personality traits and smartphone usage in daily life.

Method: 526 participants (mean age 34.57 years, $\mathrm{SD}=12.85,21 \%$ female) used the Track Your Daily Routine smartphone app (TYDR) for 48 days, on average ( $S D=63.2$, range 2 to 304). The Big Five Inventory 2 (BFI-2) was deployed to measure personality traits (Extraversion, Agreeableness, Conscientiousness, Neuroticism, and Openness). Using hierarchical linear models, we analyzed associations between personality traits and two indicators of smartphone usage: number of screen wakeups per day and session duration.

Results: Participants reached for a smartphone more frequently during weekdays with a shorter duration of usage compared to weekends. Younger people used their smartphones more often but with a shorter duration than older people. Female participants spent more time using smartphones per session than male participants. Extraversion and neuroticism were associated with more frequent checking of the phone per day while conscientiousness was associated with shorter mean session duration.

Conclusions: Frequency and duration of daily smartphone usage is associated with personality traits and participant demographics (age, gender). Implications for future research are discussed and include: integration of sensor measurements; extension with feedback functions; tracking changes in user behavior after providing information that increases awareness of his/her behavior; enabling customization of the questionnaires; and usage of AI-based functions for daily measurements.
\end{abstract}

Keywords: Smartphone usage, Usage duration, Usage frequency, Personality traits, Big Five Model
Article History

Received 14 November 2019

Revised 13 January 2020

Accepted 24 January 2020

DOI 10.24989/dp.v1i1.1821

\section{Introduction}

Communication possibilities have significantly expanded with the development of internet-based devices and applications, with the smartphone being the most popular connected device to date. The number of smartphone users surpasses three billion and is forecast to grow by several hundred million in the next few years (Holst, 2019). The finding that $95 \%$ of families in the US with children under eight years old have a smartphone indicates the level of smartphone proliferation in people's lives (Rideout, 2017).

Presently, a myriad of applications and sensors available on smartphones offer insights into human lives in a relatively direct way. As the smartphone became the most frequently used device ('Consumer device use', 2017) it opened up new possibilities for the research of human behavior. Assessing smartphone activities provides insights into a range of actual behaviors and higher precision of measured variables (Harari et al., 2016), as well as higher ecological validity (Stachl et al., 2017). In this context, analyzing patterns of smartphone usage from a computer science perspective can be a useful source of information to psychological research for the interpretation and connection of those patterns with psychological characteristics of users. The research area related to this intersection in psychological research and computer science is sometimes referred to as psychoinformatics (Markowetz et al., 2014; Montag et al., 2016; Yarkoni, 2012) or 
digital phenotyping (Baumeister \& Montag, 2019; Insel, 2017). One of the subdisciplines of psychology that could benefit from the collection of behavioral data is personality psychology, which is primarily based on self-assessment instruments (Stachl et al., 2017). Personality traits are patterns of thought, emotion, and behavior that are relatively consistent over time and across situations (Funder, 2012, p. 177). The most common personality model is The Big Five model (John \& Srivastava, 1999). It provides five broad, empirically derived traits that collectively account for the major dimensions in which individuals differ: extraversion, agreeableness, conscientiousness, neuroticism, and openness. This model inspired the development of several different personality inventories: The NEO Personality Inventory-Revised (NEO-PI-R; Costa \& McCrae, 2008), The Big Five Inventory-2 (BFI-2; Soto \& John, 2017) and the International Personality Item Pool (IPIP; Goldberg et al., 2006).

Different measures of personality traits have been used to predict many aspects of personal and professional life (Ozer \& Benet-Martínez, 2006). However, much research in personality psychology does not include measures of actual behavior (Baumeister, Vohs, \& Funder, 2007), but relies on self- and other-reports of personality. Therefore, the collection of behavioral data through the smartphone opens up new possibilities for personality research as well as higher ecological validity. With increasing technological development and extensive acceptance of smartphone usage, the possibilities for correlating digital footprints with personality traits are expanding. Regardless of user acceptance and approval, digital footprints are produced somewhat automatically by behaviors such as unlocking the smartphone, joining a Wi-Fi network, and wearing devices that track movement (Hinds \& Joinson, 2019), as well as through downloads of different applications. Algorithms can analyze smartphone usage data by determining trends of usage, which could then be used to measure and interpret the actual behavior (Hinds \& Joinson, 2019). Beierle et al., (2018) also recognized the possibility of tracking different types of data that might reflect the user's personality. They propose that smartphone's sensors can track the user's physical context, while the operating system can track the user's interaction with the smartphone and its apps. Additionally, Beierle et al., (2018) suggested a general context data model that consists of four categories. The latter focuses on the user's different interactions with smartphone physical conditions and activity, device status and usage, core functions usage, and app usage. This categorization enables research of different questions regarding the prediction of user's personality (Beierle et al., 2018a). In this current research, we focus on the category "device status and usage"; more specifically, screen wakeups (i.e., turning on the smartphone display) and duration of the usage session.

The association of the Big Five personality traits with smartphone usage has been demonstrated in several studies (Chittaranjan et al., 2013; de Montjoye et al., 2013; Harari et al., 2016, 2019; Stachl et al., 2017, 2019; Xu et al., 2016). One of the studies showed that only one personality trait, extraversion, could be predicted by smartphone usage (Mønsted et al., 2018). However, more recent studies showed that with modest prediction success and inclusion of a wide range of behavioral indicators, the trained models could predict personality traits of extraversion and openness (Harari et al., 2019), as well as conscientiousness, and some single facets of emotional stability (Stachl et al., 2019). The most common finding is the association of extraversion with increased smartphone usage, through receiving more calls (Chittaranjan et al., 2013), a higher number of calls, and intensive use of photography apps (Stachl et al., 2017). Conscientiousness was found to be associated to a higher usage of work email, but to a lower usage of YouTube, fewer voice calls (Chittaranjan et al., 2013), and to a low usage of gaming apps (Stachl et al., 2017). Individuals who score high on agreeableness tended to have more calls in general, while individuals with high emotional stability had a higher number of incoming SMS messages (Chittaranjan et al., 2013). Women with high scores on openness demonstrated greater usage of video/audio/music (Chittaranjan et al., 2013). $\mathrm{Xu}$ et al. (2016) predicted personality traits based on lists of installed apps while Schoedel et al. (2018) predicted sensation seeking behavior from a variety of smartphone-based features.

Building on this emerging research, we also explored the predictability of smartphone usage based on personality traits. We focus on two dependent variables: the frequency of the usage of the smartphone measured through number of screen wakeups; and mean duration of usage sessions per day. We also control for differences in usage depending on time of the week (weekdays vs. weekends). While existing research has investigated correlations between personality traits and mean duration of daily smartphone usage, to the best of our knowledge we are the first to disentangle these two features.

\section{Method}

\subsection{Participants}

We collected data from Android smartphone users that voluntarily installed the app TYDR - Track Your Daily Routine ${ }^{4}$ from the Google Play store (Beierle et al., 2018b). For recruitment purposes, we printed flyers, advertised TYDR in lectures ${ }^{5}$, posted on social media, and Android-related websites reported on the app. TYDR was developed solely for research purposes. The project website discloses the research question of exploring the associations between personality traits and smartphone usage.

In the 11 months of data collection, from $14^{\text {th }}$ of October 2018 to $10^{\text {th }}$ of September 2019, 3,634 users installed TYDR. The timeframe for which a user had TYDR installed depends on the decision of the user, so the installation time and the usage dura-

\footnotetext{
4 https://www.tydr.de

At Technische Universität Berlin, Berlin Psychological University, University of Kassel, University of Ulm, University of Regensburg, University of Zurich, and Danube University Krems.
} 
tion differ between users. The average usage session lasted for 3:01 minutes (median $=0: 53$, range 2 seconds to 12 hours). Of the total number of users, 765 filled out a Big Five personality traits questionnaire available in the app. For 1,052 users, there is enough data about their phone usage ${ }^{6}$ in order to utilize it in our analysis. Our sample - those that fulfilled the conditions of having filled out the Big Five questionnaire and having at least 1,000 app event log entries associated with them - contains 526 users, whose mean age is 34.57 years ( $\mathrm{SD}=12.85)$. 412 users were male $(78.3 \%)$ and 114 female $(21.7 \%)$. The mean age of the male participants was $36.00(\mathrm{SD}=13.04)$; the mean age of the female participants was $29.39(\mathrm{SD}=10.71)$.

\subsection{Mobile application TYDR}

TYDR - Track Your Daily Routine is an Android application, released in the Google Play store in October 2018. It tracks sensor data, e.g., steps or locations, and user interaction with the smartphone while running in the background. Opening the app, the user interface shows the user statistics about his/her usage of the phone and summaries of measurements from smartphone sensors. Figure 1 shows the main screen of TYDR.

Alongside the automatically tracked data, users can fill out three questionnaires: first, a demographic questionnaire with questions regarding age, gender, and highest completed level of education; second, the Big Five questionnaire which assesses individual differences in personality traits of the user; and third a questionnaire which assesses personality states and is not in the focus of this paper. The first and second questionnaire can only be completed once, while the third one can be filled out every evening.

One of the primary considerations during the development of TYDR was the focus on privacy awareness. We developed a privacy model (PM-MoDaC) for mobile data collection applications (Beierle et al., 2018a), comprising nine actions to be implemented to ensure the privacy of users of applications such as TYDR. We applied this privacy model to TYDR. It includes anonymized usage and irreversible hashing of sensitive data, for example. The study was approved by the ethics commission of the Technical University of Berlin (BEI_01_20180115).

\subsection{Measures}

Predictor variables were age, gender, time of the week, and five personality traits measured with BFI-2 (Soto \& John, 2017). Criterion variables were frequency and duration of smartphone usage sessions per day (measured in seconds irrespective of usage type).

\footnotetext{
6 We considered 1,000 app event log entries to be enough to give some insight into the user's phone usage behavior. More details are provided in the next section.
}

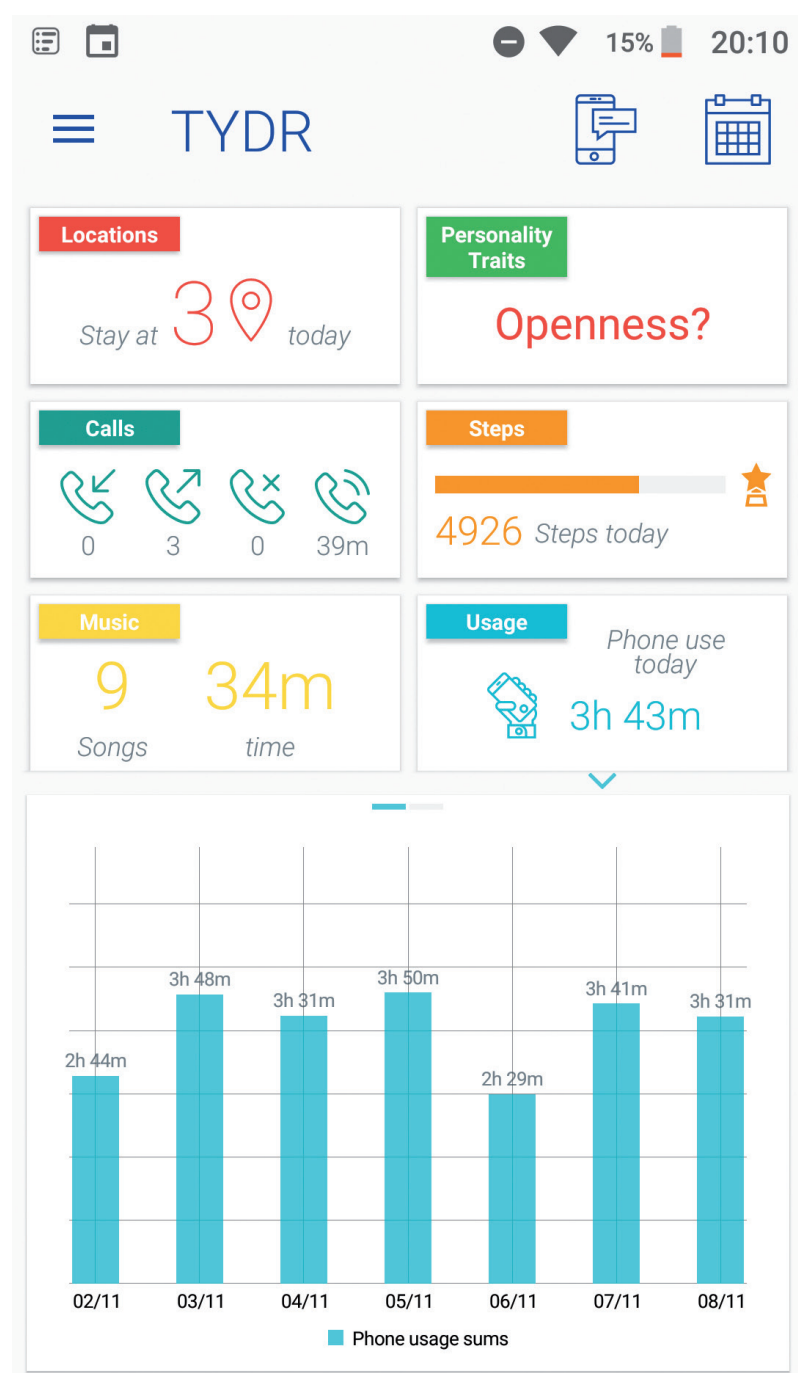

Figure 1: TYDR main screen showing smartphone sensor and usage statistics.

\subsection{BFI-2}

The Big Five personality traits were measured with the 60 -item Big Five Inventory (BFI-2; Soto \& John, 2017). This version of the questionnaire measures five personality traits: extraversion; agreeableness; conscientiousness; neuroticism; and openness. Each of the five personality traits was assessed with twelve items based on a 5-point Likert scale, ranging from 1 (strongly disagree) to 5 (strongly agree). Cronbach's Alpha $(\mathrm{n}=526)$ for each trait is as follows: extraversion $(\alpha=.82)$, agreeableness $(\alpha=.70)$, conscientiousness ( $\alpha=.82)$, neuroticism $(\alpha=.90)$, and openness $(\alpha=.81)$.

\subsection{Smartphone usage sessions}

We define a smartphone usage session as the time window in which a user was actively using the phone. Each session starts 
with turning on the display and ends with turning the screen off. We used the Android system's app event log to estimate the user's smartphone usage sessions. Each time a user opens or closes an app, the Android system records an event. ${ }^{7}$ Given the appropriate permission by the user, TYDR can access these logs and store them in the TYDR database. We implemented a heuristic for estimating actual usage sessions, including background app removal, detection, and imputation of missing events that were not recorded correctly. Based on 40,140,665 app events, our heuristic yielded 1,826,060 usage sessions in total by the 526 users in our sample. On average, users provided data across 48 days. They had on average 72 sessions per day (median $=63$, range 1 to 555), lasting for 221 seconds on average (median = 164, range 2 to 4198 ).

\subsection{Statistical Analyses}

We used $R$ ( $\mathrm{R}$ version 3.6.0, and the package lme4, sjstats, (Bates et al., 2015)) to conduct all statistical analyses (R Core Team, 2018). We used a random-intercept, random-slope multilevel regression analysis to analyze the effect of personality and time (weekday vs. weekend) on daily smartphone usage patterns (number of screen wakeups per day, mean session duration per day). The multilevel model accounts for the nested design of our study with measurement occasions aggregated on a daily level (level 1) nested within persons (level 2). We ran a baseline model without any predictors to determine the overall intraclass correlation (ICC, i.e., the relative extent to which dependent variables varied between people). We then ran a model in which weekend vs. weekday was entered at level 1 and age, gender, extraversion, openness, neuroticism, agreeableness, and conscientiousness simultaneously entered on level 2 (level 2 variables were all grandmean centered except Gender; Enders \& Tofighi, 2007) ${ }^{8}$.

The final model is displayed below:

Level 1 (within person): Wakeups per day [Mean session duration per day $]_{\mathrm{ti}}=\pi_{0 \mathrm{i}}+\pi_{\mathrm{li}}$ Weekday vs. Weekend $\mathrm{ti}_{\mathrm{ti}}+e_{\mathrm{ti}}$

Level 2 (between people): $\pi_{0 \mathrm{i}}=\beta_{00}+\beta_{01}$ Age $_{\mathrm{i}}+\beta_{02}$ Gender $_{\mathrm{i}}+\beta_{03}$ Extraversion $_{i}+\beta_{04}$ Agreeableness $_{i}+\beta_{05}$ Conscientiousness $_{i}+\beta_{06}$ Neuroticism $_{\mathrm{i}}+\beta_{07}$ Openness $_{\mathrm{i}}+r_{0 \mathrm{i}}$

Level 2: $\pi_{1 \mathrm{i}}=\beta_{10}+r_{1 \mathrm{i}}$

We used $R_{\text {GLMM }}^{2}$ (Nakagawa et al., 2017; Nakagawa \& Schielzeth, 2013) as a measure of explained variance, which can be inter-

\footnotetext{
Additionally, other app events are recorded for other types of actions of apps. For the usage session estimation, we only need the events for opening an app to the foreground and closing it.

8 We have also calculated the models by including the number of days participants had the TYDR app installed as a measure of participant motivation. Because this predictor was non-significant in all models, we excluded this predictor on the basis of efficiency.
}

preted like the traditional $R^{2}$ statistic in regression analyses. $R_{\text {marginal }}^{2}$ represents the proportion of variance explained by the fixed effects alone. As the effect size measure, we used standardized $\beta$ and $95 \%$ confidence intervals.

One might argue that the act of having installed the app and getting regular feedback about one's usage patterns may in and of itself change one's behavior. To account for this, we calculated MLMs with an additional variable at level 1 reflecting the time since the first usage of TYDR. Because this variable revealed only tiny effects and beta values for the other predictors did not substantially change, we did not include this variable into the final analyses in order to keep the model comprehensible.

\section{Results}

The multilevel analysis revealed several statistically significant predictors of smartphone usage (see Table 1; for intercorrelations, see Table S1 in the online supplement), respectively: time of the week (weekdays vs weekends); age; gender; and three personality traits (extraversion, neuroticism and conscientiousness). ${ }^{9}$

In more detail, there was a noticeably lower number of screen wakeups during weekends compared to weekdays ( $\beta=-.10,95 \%$ CI $[-.11,-.08])$. On the other hand, mean session duration per day $(\beta=.06,95 \%$ CI $[.04, .07])$ was higher during the weekend compared to the weekdays. That means that reaching for a smartphone was more frequent during weekdays with shorter duration of usage, while during a weekend screen wakeups were less frequent but the mean duration of sessions per day was longer.

Age was a significant negative predictor for the number of screen wakeups per day $(\beta=-.19,95 \%$ CI $[-.25,-.13])$ and a significant positive for the mean session duration per day $(\beta=.06$, $95 \%$ CI $[.01, .12])$. Younger individuals had a higher number of screen wakeups per day, while older individuals had higher mean session durations per day. In other words, younger people seem to check their smartphone more often, but with a shorter duration, while older individuals spend more time using their smartphone per session.

Participants' gender was also a significant predictor for the mean session duration per day $(\beta=-.06,95 \%$ CI $[-.12,-.01])$, meaning that female participants spent 31.6 seconds more time per session than males.

Extraversion was a significant predictor for the number of screen wakeups per day $(\beta=.11,95 \%$ CI $[.04, .17])$, meaning that higher extraversion was associated with more frequent smartphone checking. Additionally, neuroticism was also a significant predictor for the same variable $(\beta=.12,95 \%$ CI $[.05$, $.18]$ ), which means that higher neuroticism was associated with higher number of the phone checking per day. The personality trait conscientiousness was also found to be a significant predic-

9 For possible gender $*$ personality interactions, see supplementary table $\mathrm{S} 2$. 
Beierle, F., Probst, T., Allemands, M., Zimmermann, J., Pryss, R., Neff, P., Schlee, W., Stieger, S. \& Budimir, S.

Table 1. Results of the multi-level analysis.

\begin{tabular}{|c|c|c|c|c|c|c|c|c|}
\hline & & \multicolumn{4}{|c|}{ Fixed } & \multicolumn{3}{|c|}{ Random } \\
\hline & Coeff. & $\beta$ & $95 \% \mathrm{Cl}$ & $B$ & SE & $t$ & Coeff. & $S D$ \\
\hline \multicolumn{9}{|c|}{ Screen wakeups per day } \\
\hline Intercept & $\beta_{00}$ & & & 72.0 & 3.14 & $22.89^{* * *}$ & $r_{0 i}$ & 33.9 \\
\hline \multicolumn{9}{|l|}{ Within-person } \\
\hline Weekend (ref weekday) & $\beta_{10}$ & -.10 & $-.11--.08$ & -9.6 & 0.82 & $-11.78^{* * *}$ & $r_{1 i}$ & 13.8 \\
\hline \multicolumn{9}{|l|}{ Between-person } \\
\hline Age & $\beta_{01}$ & -.19 & $-.25--.13$ & -0.7 & 0.11 & $-6.21^{\star * *}$ & & \\
\hline Gender (ref female) & $\beta_{02}$ & .04 & $-.02-.10$ & 4.2 & 3.52 & 1.20 & & \\
\hline Extraversion & $\beta_{03}$ & .11 & $.04-.17$ & 7.2 & 2.33 & $3.08^{* *}$ & & \\
\hline Agreeableness & $\beta_{04}$ & $>-.01$ & $-.07-.06$ & -0.3 & 2.86 & -0.10 & & \\
\hline Conscientiousness & $\beta_{05}$ & .01 & $-.06-.07$ & 0.6 & 2.28 & 0.26 & & \\
\hline Neuroticism & $\beta_{06}$ & .12 & $.05-.18$ & 6.6 & 1.96 & $3.34^{* * *}$ & & \\
\hline Openness & $\beta_{07}$ & -.02 & $-.08-.05$ & -1.0 & 2.16 & -0.46 & & \\
\hline \multicolumn{9}{|c|}{$\mathrm{ICC}=57.5 \%, \mathrm{R}_{\text {marginal }}^{2}=6.5 \%$} \\
\hline \multicolumn{9}{|c|}{ Mean session duration per day } \\
\hline Intercept & $\beta_{00}$ & & & 225.0 & 12.50 & $18.01^{* * *}$ & $\mathrm{r}_{0 \mathrm{i}}$ & 120.0 \\
\hline \multicolumn{9}{|l|}{ Within-person } \\
\hline Weekend (ref weekday) & $\beta_{10}$ & .06 & $.04-.07$ & 26.1 & 3.11 & $8.38^{* * *}$ & $r_{1 i}$ & 37.9 \\
\hline \multicolumn{9}{|l|}{ Between-person } \\
\hline Age & $\beta_{01}$ & .06 & $.01-.12$ & 1.0 & 0.45 & $2.28^{*}$ & & \\
\hline Gender (ref female) & $\beta_{02}$ & -.06 & $-.12--.01$ & -31.6 & 14.31 & $-2.21^{*}$ & & \\
\hline Extraversion & $\beta_{03}$ & $<.01$ & $-.06-.06$ & 0.6 & 9.49 & 0.06 & & \\
\hline Agreeableness & $\beta_{04}$ & -.02 & $-.07-.04$ & -6.8 & 11.65 & -0.59 & & \\
\hline Conscientiousness & $\beta_{05}$ & -.14 & $-.20--.08$ & -41.1 & 9.28 & $-4.43^{* * *}$ & & \\
\hline Neuroticism & $\beta_{06}$ & .01 & $-.05-.08$ & 3.8 & 7.98 & 0.48 & & \\
\hline Openness & $\beta_{07}$ & .03 & $-.03-.09$ & 8.7 & 8.81 & 1.00 & & \\
\hline
\end{tabular}

Note. All level 2 variables were grand mean centered except for gender and weekend. CI = Confidence Interval. ${ }^{\star} p<.05,{ }^{* *} p<.01,{ }^{* * *} p<.001$.

tor for the mean session duration per day $(\beta=-.14,95 \%$ CI $[-.20$, $-.08])$. That means that a high conscientiousness was associated with a shorter duration of the session per day.

Furthermore, because our criterion measures were nonnormally distributed, we recalculated all analyses by using log- transformed measures of Screen wakeups per day and Mean session duration per day. None of the significances changed except for the Mean session duration per day analysis, where the very small effect for gender $(\beta=-.06$, see Table 1$)$ was now no longer significant $(\beta=-.05, p=.14$; detailed results omitted for brevity). 
In order to keep the beta values interpretable, we present the results for the non-log-transformed criterion measures.

Additionally, we analyzed a potential self-selection bias (i.e., participants might be different from non- participants) regarding our dependent variables (non- participants: $n=523$ ). We calculated MLMs with only the group variable (participant vs. non-participant) as the predictor. We did not find any significant differences, neither for wakeup frequencies, nor for session duration on a day level (detailed results omitted for brevity).

\section{Discussion}

This study evaluated whether personality traits are associated with smartphone usage. We found that both extraversion and neuroticism were associated with a higher number of screen wakeups per day, and conscientiousness was related to shorter session durations per day.

Our results regarding extraversion are broadly in line with previous studies showing connections of extraversion with higher frequency and duration of calls or other communication behavior (Baumeister \& Montag, 2019; Chittaranjan et al., 2013; Harari et al., 2019; Mønsted et al., 2018; Montag et al., 2019, 2014; Stachl et al., 2019, 2017). In the study by Chittaranjan et al. (2013), emotional stability was connected to a higher number of incoming SMS messages, while our study showed neuroticism to be related to a higher usage of the smartphone measured as the number of wakeups per day. Azucar et al. (2018) reported individuals who are highly conscientious are using social media less. Our results showed decreased usage for conscientious users as well, as those individuals tend to have shorter duration of smartphone usage sessions. Montag et al. (2015) investigated correlations between gender, age, personality, and usage of WhatsApp. Similar to our findings about general smartphone usage, they reported that female and younger users were using WhatsApp more, while conscientiousness was correlated with a shorter length of WhatsApp usage. Andone et al. (2016) reported similar findings about age, gender, and smartphone usage. They reported that the daily mean of phone usage time was higher for female and younger participants but did not investigate wakeup frequencies or correlations with personality.

We can speculate somewhat about the nature of the relationships between neuroticism and extraversion and higher phone usage. For extraversion, the reason for increased usage might be social, e.g., checking the phone for a message that came in (Costa \& McCrae, 2008; Goldberg et al., 2006). For higher levels of neuroticism, the reason might be anxiousness with respect to missing important things (Stead \& Bibby, 2017). Longer usage sessions on weekends could indicate that there is more time for longer searches or tasks. We do not know if the smartphone was used by the user only for private purposes, only for business purposes, or for both. More screen wakeups during weekdays could also be a result of work-related phone usage, which is lesser during weekends. Younger people might show a different phone usage pattern because they might demonstrate a different approach to technology in general. Users scoring higher on the trait of conscientiousness maybe consciously reduce their phone usage to not be distracted (Costa \& McCrae, 2008). Further studies are required to confirm these interpretations. Analyses of used apps during the usage sessions could also deepen the understanding of the relationship between personality traits and smartphone usage.

When interpreting the results of the present study, several limitations have to be considered. On a technical level, usage session estimation is not as straightforward as it seems. One way to track smartphone usage is to track the display's state. It can only be tracked while TYDR is running. Due to fragmentation - having many different devices with different Android versions and different software adaptations by smartphone manufacturers - and because other apps can interfere with background processes, it is not always possible to ensure that an app is not closed while running in the background. This leads to display state events being missed. Given these constraints, we opted to use the Android system's app event log to determine usage sessions. In contrast to the display state events, Android itself already records the app events. This has the advantage that even when TYDR is not running for some time, the app events can still be tracked. The errors and potentially faulty records that we found in the app event logs were processed by a simple heuristic that we implemented which removed background apps and imputed missing app closing events.

Although our sample was relatively large, it was not representative. Moreover, we have to consider that our results might be biased by excluding users who did not provide enough app event $\log$ entries (of 3,634 users who installed the app, only 526 could be analyzed). Another limitation relates to the smartphone behaviors analyzed in the current study. It is important to state that usage behaviors only reflect a small percentage of data that it is possible to collect with passive sensing technology (Ben-Zeev et al., 2015; Cornet \& Holden, 2018). For example, geospatial data (e.g., by GPS) would be additional behavioral data that can be monitored with smartphones (e. g., Kerr, Duncan, \& Schipperjin, 2011; Pryss et al., 2019). While also tracking the usage behavior of iOS users would potentially increase the user base, research suggests that such a study would likely yield similar results (Götz et al., 2017). Additionally, this study is only correlational therefore does not provide information about causal relations between frequency and duration of daily smartphone usage in relation to personality traits.

Despite the limitations, the study has a number of strengths. The data was collected in daily life and this increases the ecological validity of the results. Compared to many previous studies, our sample was relatively large, improving the precision of our results. The findings indicate that, for TYDR users, personality traits were associated with smartphone usage.

There are several directions in which future work in this area could be taken. One direction could be to integrate sensor measurements that gather, for example, vital signs, which might be then correlated with the smartphone-based indicators. Second, 
the app could be extended with feedback functions that investigate the smartphone-based indicators by influencing them purposefully (e.g., Rabbi, Klasnja, Choudhury, Tewari, \& Murphy, 2019). For example, the app could learn based on gathered GPS data, which movement behavior is beneficial for a user. Such behavior could then be recommended to a user. Third is the possibility to make the user aware of his/her behavior and track the changes after providing such information. Fourth, the users could be enabled to adapt the questionnaires to their individual needs. Fifth, recent smartphones are often equipped with CPUs (central processing units) that incorporate Artificial intelligence (AI)-based functions. The latter are used, for example, to save resources on the smartphone. If such features are beneficial, then they can be exploited for TYDR. On the other, if such features are unfavorable, then they should be addressed by the implementation of TYDR. As an example, if notifications are automatically deactivated by AI-based functions due to a low battery, then such behavior is not intended for the study and must be addressed.

\section{References}

Andone, I., Błaszkiewicz, K., Eibes, M., Trendafilov, B., Montag, C., \& Markowetz, A. (2016). How age and gender affect smartphone usage. Proceedings of the 2016 ACM International Joint Conference on Pervasive and Ubiquitous Computing Adjunct - UbiComp '16, 9-12. https://doi.org/10.1145/2968219.2971451

Azucar, D., Marengo, D., \& Settanni, M. (2018). Predicting the Big 5 personality traits from digital footprints on social media: A metaanalysis. Personality and Individual Differences, 124, 150-159. https://doi.org/10.1016/j.paid.2017.12.018

Bates, D., Mächler, M., Bolker, B., \& Walker, S. (2015). Fitting Linear Mixed-Effects Models Using lme4. Journal of Statistical Software, 67(1). https://doi.org/10.18637/jss.v067.i01

Baumeister, H., \& Montag, C. (Eds.). (2019). Digital Phenotyping and Mobile Sensing: New Developments in Psychoinformatics. Springer International Publishing. https://doi.org/10.1007/978-3-030-31620-4

Baumeister, R. F., Vohs, K. D., \& Funder, D. C. (2007). Psychology as the Science of Self-Reports and Finger Movements: Whatever Happened to Actual Behavior? Perspectives on Psychological Science, 2(4), 396-403. https://doi.org/10.1111/j.1745-6916.2007.00051.

Beierle, F., Tran, V. T., Allemand, M., Neff, P., Schlee, W., Probst, T., Pryss, R., \& Zimmermann, J. (2018a). Context Data Categories and Privacy Model for Mobile Data Collection Apps. Procedia Computer Science, 134, 18-25. https://doi.org/10.1016/j.procs.2018.07.139

Beierle, F., Tran, V. T., Allemand, M., Neff, P., Schlee, W., Probst, T., Pryss, R., \& Zimmermann, J. (2018b). TYDR: Track your daily routine. Android app for tracking smartphone sensor and usage data. Proceedings of the 5th International Conference on Mobile Software Engineering and Systems - MOBILESoft '18, 72-75. https://doi. org/10.1145/3197231.3197235

Ben-Zeev, D., Scherer, E. A., Wang, R., Xie, H., \& Campbell, A. T. (2015). Next-generation psychiatric assessment: Using smartphone sensors to monitor behavior and mental health. Psychiatric Rehabilitation Journal, 38(3), 218-226. https://doi.org/10.1037/prj0000130
Chittaranjan, G., Blom, J., \& Gatica-Perez, D. (2013). Mining large-scale smartphone data for personality studies. Personal and Ubiquitous Computing, 17(3), 433-450. https://doi.org/10.1007/s00779-0110490-1

Consumer device use: Which gadgets get used most frequently? (2017, October 11). Verto Analytics. https://vertoanalytics.com/chart-ofthe-week-which-devices-are-used-most-often/

Cornet, V. P., \& Holden, R. J. (2018). Systematic review of smartphonebased passive sensing for health and wellbeing. Journal of Biomedical Informatics, 77, 120-132. https://doi.org/10.1016/j.jbi.2017.12.008

Costa, P. T., \& McCrae, R. R. (2008). The Revised NEO Personality Inventory (NEO-PI-R). In The SAGE Handbook of Personality Theory and Assessment: Volume 2-Personality Measurement and Testing (pp. 179-198). SAGE Publications Ltd. https://doi. org/10.4135/9781849200479.n9

de Montjoye, Y.-A., Quoidbach, J., Robic, F., \& Pentland, A. (2013). Predicting Personality Using Novel Mobile Phone-Based Metrics. In A. M. Greenberg, W. G. Kennedy, \&N.D. Bos (Eds.), Social Computing, Behavioral-Cultural Modeling and Prediction (Vol. 7812, pp. 48-55). Springer Berlin Heidelberg. https://doi.org/10.1007/978-3-642-37210-0_6

Enders, C. K., \& Tofighi, D. (2007). Centering predictor variables in cross-sectional multilevel models: A new look at an old issue. Psychological Methods, 12(2), 121-138. https://doi.org/10.1037/1082989X.12.2.121

Funder, D. C. (2012). Accurate Personality Judgment. Current Directions in Psychological Science, 21(3), 177-182. https://doi. org/10.1177/0963721412445309

Goldberg, L. R., Johnson, J. A., Eber, H. W., Hogan, R., Ashton, M. C., Cloninger, C. R., \& Gough, H. G. (2006). The international personality item pool and the future of public-domain personality measures. Journal of Research in Personality, 40(1), 84-96. https://doi. org/10.1016/j.jrp.2005.08.007

Götz, F. M., Stieger, S., \& Reips, U.-D. (2017). Users of the main smartphone operating systems (iOS, Android) differ only little in personality. PLOS ONE, 12(5), e0176921. https://doi.org/10.1371/journal. pone. 0176921

Harari, G. M., Lane, N. D., Wang, R., Crosier, B. S., Campbell, A. T., \& Gosling, S. D. (2016). Using Smartphones to Collect Behavioral Data in Psychological Science: Opportunities, Practical Considerations, and Challenges. Perspectives on Psychological Science, 11(6), 838-854. https://doi.org/10.1177/1745691616650285

Harari, G. M., Müller, S. R., Stachl, C., Wang, R., Wang, W., Bühner, M., Rentfrow, P. J., Campbell, A. T., \& Gosling, S. D. (2019). Sensing sociability: Individual differences in young adults' conversation, calling, texting, and app use behaviors in daily life. Journal of Personality and Social Psychology. https://doi.org/10.1037/pspp0000245

Hinds, J., \& Joinson, A. (2019). Human and Computer Personality Prediction From Digital Footprints. Current Directions in Psychological Science, 28(2), 204-211. https://doi.org/10.1177/0963721419827849

Holst, A. (2019, December). Smartphone users worldwide 2016-2021. Statista. https://www.statista.com/statistics/330695/number-ofsmartphone-users-worldwide/

Insel, T. R. (2017). Digital Phenotyping: Technology for a New Science of Behavior. JAMA, 318(13), 1215. https://doi.org/10.1001/ jama.2017.11295

John, O. P., \& Srivastava, S. (1999). The Big Five Trait taxonomy: History, measurement, and theoretical perspectives. In Handbook of personality: Theory and research, 2nd ed (pp. 102-138). Guilford Press. 
Kerr, J., Duncan, S., \& Schipperjin, J. (2011). Using Global Positioning Systems in Health Research. American Journal of Preventive Medicine, 41(5), 532-540. https://doi.org/10.1016/j.amepre.2011.07.017

Markowetz, A., Błaszkiewicz, K., Montag, C., Switala, C., \& Schlaepfer, T. E. (2014). Psycho-Informatics: Big Data shaping modern psychometrics. Medical Hypotheses, 82(4), 405-411. https://doi. org/10.1016/j.mehy.2013.11.030

Mønsted, B., Mollgaard, A., \& Mathiesen, J. (2018). Phone-based metric as a predictor for basic personality traits. Journal of Research in Personality, 74, 16-22. https://doi.org/10.1016/j.jrp.2017.12.004

Montag, C., Baumeister, H., Kannen, C., Sariyska, R., Meßner, E.-M., \& Brand, M. (2019). Concept, Possibilities and Pilot-Testing of a New Smartphone Application for the Social and Life Sciences to Study Human Behavior Including Validation Data from Personality Psychology. J, 2(2), 102-115. https://doi.org/10.3390/j2020008

Montag, C., Błaszkiewicz, K., Lachmann, B., Andone, I., Sariyska, R., Trendafilov, B., Reuter, M., \& Markowetz, A. (2014). Correlating Personality and Actual Phone Usage: Evidence From Psychoinformatics. Journal of Individual Differences, 35(3), 158-165. https://doi. org/10.1027/1614-0001/a000139

Montag, C., Błaszkiewicz, K., Sariyska, R., Lachmann, B., Andone, I., Trendafilov, B., Eibes, M., \& Markowetz, A. (2015). Smartphone usage in the 21st century: Who is active on WhatsApp? BMC Research Notes, 8(1), 331. https://doi.org/10.1186/s13104-015-1280-z

Montag, C., Duke, É., \& Markowetz, A. (2016). Toward Psychoinformatics: Computer Science Meets Psychology. Computational and Mathematical Methods in Medicine, 2016, 1-10. https://doi. org/10.1155/2016/2983685

Nakagawa, S., Johnson, P. C. D., \& Schielzeth, H. (2017). The coefficient of determination $R^{2}$ and intra-class correlation coefficient from generalized linear mixed-effects models revisited and expanded. Journal of The Royal Society Interface, 14(134), 20170213. https://doi. org/10.1098/rsif.2017.0213

Nakagawa, S., \& Schielzeth, H. (2013). A general and simple method for obtaining $R^{2}$ from generalized linear mixed-effects models. Methods in Ecology and Evolution, 4(2), 133-142. https://doi.org/10.1111/ j.2041-210x.2012.00261.x

Ozer, D. J., \& Benet-Martínez, V. (2006). Personality and the Prediction of Consequential Outcomes. Annual Review of Psychology, 57(1), 401-421. https://doi.org/10.1146/annurev.psych.57.102904.190127

Pryss, R., John, D., Reichert, M., Hoppenstedt, B., Schmid, L., Schlee, W., Spiliopoulou, M., Schobel, J., Kraft, R., Schickler, M., Langguth, B., \& Probst, T. (2019). Machine Learning Findings on Geospatial Data of Users from the TrackYourStress mHealth Crowdsensing Platform. 2019 IEEE 20th International Conference on Information Reuse and Integration for Data Science (IRI), 350-355. https://doi. org/10.1109/IRI.2019.00061

R Core Team. (2018). R: A language and environment for statistical computing. R Foundation for Statistical Computing, Vienna, Austria. https://www.R-project.org/

Rabbi, M., Klasnja, P., Choudhury, T., Tewari, A., \& Murphy, S. (2019). Optimizing mHealth Interventions with a Bandit. In H. Baumeister \& C. Montag (Eds.), Digital Phenotyping and Mobile Sensing (pp. 277-291). Springer International Publishing. https://doi. org/10.1007/978-3-030-31620-4_18

Rideout, V. (2017). The common sense census: Media use by kids age zero to eight. Common Sense Media. https://www.commonsensemedia. org/zero-to-eight-census-infographic.
Schoedel, R., Au, Q., Völkel, S. T., Lehmann, F., Becker, D., Bühner, M., Bischl, B., Hussmann, H., \& Stachl, C. (2018). Digital Footprints of Sensation Seeking: A Traditional Concept in the Big Data Era. Zeitschrift Für Psychologie, 226(4), 232-245. https://doi. org/10.1027/2151-2604/a000342

Soto, C. J., \& John, O. P. (2017). The next Big Five Inventory (BFI-2): Developing and assessing a hierarchical model with 15 facets to enhance bandwidth, fidelity, and predictive power. Journal of Personality and Social Psychology, 113(1), 117-143. https://doi.org/10.1037/ pspp0000096

Stachl, C., Au, Q., Schoedel, R., Buschek, D., Völkel, S., Schuwerk, T., Oldemeier, M., Ullmann, T., Hussmann, H., Bischl, B., \& Bühner, M. (2019). Behavioral Patterns in Smartphone Usage Predict Big Five Personality Traits [Preprint]. PsyArXiv. https://doi.org/10.31234/osf. io/ks4vd

Stachl, C., Hilbert, S., Au, J.-Q., Buschek, D., De Luca, A., Bischl, B., Hussmann, H., \& Bühner, M. (2017). Personality Traits Predict Smartphone Usage: Personality traits predict smartphone usage. European Journal of Personality, 31(6), 701-722. https://doi. org/10.1002/per.2113

Stead, H., \& Bibby, P. A. (2017). Personality, fear of missing out and problematic internet use and their relationship to subjective wellbeing. Computers in Human Behavior, 76, 534-540. https://doi. org/10.1016/j.chb.2017.08.016

Xu, R., Frey, R. M., Fleisch, E., \& Ilic, A. (2016). Understanding the impact of personality traits on mobile app adoption - Insights from a large-scale field study. Computers in Human Behavior, 62, 244-256. https://doi.org/10.1016/j.chb.2016.04.011

Yarkoni, T. (2012). Psychoinformatics: New Horizons at the Interface of the Psychological and Computing Sciences. Current Directions in Psychological Science, 21(6), 391-397. https://doi.org/10.1177/ 0963721412457362

\section{*Corresponding Author}

\section{Felix Beierle}

beierle@tu-berlin.de

$+4930835354265$

\section{Funding}

This work has received funding in the context of project DYNAMIC (grant No 01IS12056), which is funded as part of the Software Campus initiative by the German Federal Ministry of Education and Research (BMBF).

\section{Author contributions}

F.B., T.P., M.A., J.Z., R.P., P.N., W.S. are part of the TYDR team and contributed with ideas to the development of the TYDR app, F.B. had the lead in programming the TYDR app and drafted the manuscript, T.P. contributed the study idea and revised the manuscript, M.A. revised the manuscript, J.Z. revised the manuscript and contributed to the statistical analyses, R.P. revised the manuscript, P.N. revised the manuscript and contributed to the statistical analyses, W.S. revised the manuscript and contributed to the statistical analyses; S.S. performed the statistical analyses, S.B. drafted the manuscript. 
Beierle, F., Probst, T., Allemands, M., Zimmermann, J., Pryss, R., Neff, P., Schlee, W., Stieger, S. \& Budimir, S.

\section{Supplementary Material}

Table S1. Descriptives and intercorrelations.

\begin{tabular}{|c|c|c|c|c|c|c|c|}
\hline & $M(S D)$ & 1 & 2 & 3 & 4 & 5 & 6 \\
\hline 1. Age & $34.6(12.85)$ & & & & & & \\
\hline 2. Gender & - & $.21^{* * *}$ & & & & & \\
\hline 3. Extraversion & $3.1(0.66)$ & -.06 & -.01 & & & & \\
\hline 4. Agreeableness & $3.7(0.51)$ & .06 & $-.11^{* *}$ & $.12^{\star *}$ & & & \\
\hline 5. Conscientiousness & $3.4(0.65)$ & $.14^{* *}$ & -.03 & $.27^{* * *}$ & $.18^{* * *}$ & & \\
\hline 6. Neuroticism & $2.9(0.82)$ & $-.14^{* *}$ & $-.21 * * *$ & $-.33^{* * *}$ & $-.32^{\star * *}$ & $-.31 * * *$ & \\
\hline 7. Openness & $3.6(0.66)$ & $-.11 *$ & -.06 & $.26^{* * *}$ & $.10^{*}$ & .07 & .01 \\
\hline
\end{tabular}

Note: sex: 1. female, 2. male

Table S2. Results of the multi-level analysis by including gender ${ }^{\star}$ personality interactions.

\begin{tabular}{|c|c|c|c|c|c|c|c|}
\hline & \multicolumn{5}{|c|}{ Fixed } & \multicolumn{2}{|c|}{ Random } \\
\hline & $\beta$ & $95 \% \mathrm{Cl}$ & $B$ & SE & $t$ & Coeff. & $S D$ \\
\hline \multicolumn{8}{|c|}{ Screen wakeups per day } \\
\hline Intercept & & & 69.4 & 3.49 & $19.87^{* * *}$ & $r_{0 \mathrm{i}}$ & 34.04 \\
\hline \multicolumn{8}{|l|}{ Within-person } \\
\hline Weekend (ref weekday) & -.10 & $-.11--.08$ & -9.6 & 0.82 & $-11.77^{* * *}$ & $r_{1 i}$ & 13.85 \\
\hline \multicolumn{8}{|l|}{ Between-person } \\
\hline Age & -.20 & $-.26--.14$ & -0.7 & 0.11 & $-6.31^{* * *}$ & & \\
\hline Gender (ref female) & .06 & $-.01-.12$ & 6.6 & 3.78 & $1.75+$ & & \\
\hline Extraversion & .13 & $-.01-.26$ & 8.5 & 4.52 & $1.89+$ & & \\
\hline Agreeableness & .01 & $-.12-.14$ & 0.9 & 6.00 & 0.16 & & \\
\hline Conscientiousness & -.01 & $-.13-.12$ & -0.5 & 4.27 & -0.12 & & \\
\hline Neuroticism & .25 & $.11-.40$ & 14.3 & 4.20 & $3.40^{* * *}$ & & \\
\hline Openness & -.03 & $-.16-.10$ & -2.0 & 4.18 & -0.78 & & \\
\hline Gender * Extraversion & -.03 & $-.16-.10$ & -2.0 & 5.26 & -0.38 & & \\
\hline Gender * Agreeableness & -.01 & $-.14-.12$ & -1.3 & 6.84 & -0.19 & & \\
\hline Gender * Conscientiousness & .02 & $-.11-.15$ & 1.7 & 5.04 & 0.33 & & \\
\hline Gender * Neuroticism & -.16 & $-.31--.01$ & -10.1 & 4.74 & $-2.12^{*}$ & & \\
\hline Gender * Openness & .02 & $-.11-.15$ & 1.3 & 4.88 & 0.27 & & \\
\hline \multicolumn{8}{|c|}{$\mathrm{ICC}=57.3 \%, \mathrm{R}_{\text {marginal }}^{2}=6.8 \%$} \\
\hline \multicolumn{8}{|c|}{ Mean session duration per day } \\
\hline Intercept & & & 229.1 & 13.98 & $16.39^{\star * *}$ & $r_{0 i}$ & 120.28 \\
\hline \multicolumn{8}{|l|}{ Within-person } \\
\hline Weekend (ref weekday) & .06 & $.05-.07$ & 26.1 & 3.12 & $8.37^{* * *}$ & $r_{1 i}$ & 37.92 \\
\hline \multicolumn{8}{|l|}{ Between-person } \\
\hline Age & .06 & $.01-.12$ & 1.0 & 0.45 & $2.10^{*}$ & & \\
\hline Gender (ref female) & -.07 & $-.13--.01$ & -35.3 & 15.45 & $-2.29^{*}$ & & \\
\hline Extraversion & .01 & $-.11-.13$ & 2.2 & 18.44 & 0.12 & & \\
\hline Agreeableness & -.08 & $-.20-.04$ & -32.8 & 24.60 & -0.133 & & \\
\hline Conscientiousness & -.17 & $-.29--.06$ & -53.1 & 17.45 & $-3.05^{\star *}$ & & \\
\hline Neuroticism & .01 & $-.13-.14$ & 1.6 & 17.12 & 0.09 & & \\
\hline Openness & .02 & $-.10-.13$ & 4.5 & 17.06 & 0.27 & & \\
\hline Gender * Extraversion & -.01 & $-.13-.11$ & -3.8 & 21.49 & -0.18 & & \\
\hline Gender * Agreeableness & .07 & $-.05-.19$ & 33.2 & 28.03 & 1.19 & & \\
\hline Gender * Conscientiousness & .05 & $-.07-.16$ & 16.0 & 20.60 & 0.78 & & \\
\hline Gender * Neuroticism & .01 & $-.13-.14$ & 2.0 & 19.36 & 0.10 & & \\
\hline Gender * Openness & .02 & $-.10-.14$ & 6.3 & 19.94 & 0.32 & & \\
\hline
\end{tabular}

Note. $+p<.10,{ }^{\star} p<.05,{ }^{* *} p<.01,{ }^{* *} p<.001$. 